\title{
The role of coastal water quality for tourism demand and regional economy - Coupling ecological and economic models
}

\author{
Jesko Hirschfield, IOeW, Berlin, Germany
}

\begin{abstract}
The Oder Estuary is currently highly polluted by nutrients from agriculture and insufficiently treated wastewater in the Oder river basin. Eutrophication causes algal blooms and low water transparency within the Oder Estuary. Thereby tourism and economic development within the region are severely hampered. But to find good arguments for costly nutrient reduction measures in the upper Oder catchment region, the effects of water quality improvements in the coastal area have to be quantified. In the current study water transparency serves as the major link between ecology and economy. It is determined by the concentration of particles and dissolved substances and reflects the intensity of authochthonous primary production, the resuspension of sediment as well as the input of allochthonous material. With reference to previous studies it is assumed that water transparency is a suitable indicator for the state of eutrophication in Baltic coastal waters. The tourism sector model takes water transparency as one of the independent variables that influence the demand for beach visits and thereby the number of tourists at the beach (other independent variables and infrastructure weather water temperature and income) Beach visitors are to certain percentages day visitors or are staying overnight. By expenditure functions they contribute to the regional product of tourism sector. This in turn generates employment income to employees and owners of the regional tourism industry as well as investment into the tourism infrastructure. Growth in regional product of the tourism sector thereby increases with the supply of regional tourism services, causing a feedback loop via the interaction with demand for these tourism services. To evaluate the variables determining the demand for beach visits (asnd thereby, as explained above, assessing variables influencing the regional product of the tourism industry) a questionnaire containing a choice experienced was designed pre-tested translated and used in an on-site interview campaign in the German and Polish Oder Estuary region. 450 visitors were interviewed. One of the results is the willingness to pay for an improvement in water transparency. The empirical results are used to specify the demand function for beach visits and contribute to the calculation of the total economic value of coastal ecosystem services. A regional economic model then deducts effects of regional economic product, tax revenues and employment.
\end{abstract}

